\title{
Characteristics of Sediment Removal in Two Types of Permeable Pavement
}

\author{
Chris Brown, ${ }^{1}$ Angus Chu, ${ }^{1}$ Bert van Duin,,${ }^{1,2}$ and Caterina Valeo ${ }^{1 *}$ \\ ${ }^{1}$ Civil Engineering, Schulich School of Engineering, University of Calgary 2500 University Drive NW, Calgary, \\ Alberta, Canada T2N 1N4 \\ ${ }^{2}$ Wardrop Engineering Inc. - A Tetra Tech Company, Calgary, Alberta (formerly Westhoff Engineering Resources Inc.)
}

This study investigates the processes and characteristics of solids removal in two types of permeable pavement: UNI EcoStone and porous asphalt. The mechanisms and processes behind solids removal within permeable pavement structures was studied for these two types of permeable pavements using both field installations and laboratory experiments. Results from the study showed that both pavement types are capable of excellent total suspended solids removal, in the range of 90 to $96 \%$ removal of solids from influent. Particle size distribution analysis of accumulated sediment within the pavement structure and in the influent and effluent showed that the particles in the effluent of the pavements are substantially finer than that in the influent. Laboratory results involving no crust formation indicated that, although solids removal occurs throughout the entire structure, the "sieving action" occurs primarily at the geotextile interface.

Key words: permeable pavement, total suspended solids, best management practices, particle size distributions, porous pavement

\section{Introduction}

The use of permeable pavements as a method for improving the management and treatment of stormwater has increased dramatically over the past decade. The potential to reduce or eliminate the need for traditional stormwater infrastructure by use of low impact development (LID) technologies has become an important area of research and discussion within the stormwater management profession. Designers, city planners, and stormwater management engineers across Europe, North America, and Australia have begun exploring the use of this best management practice (BMP) as a promising, cost-effective way to address the problem of increased stormwater runoff and decreased stream water quality associated with urbanization (Brattebo and Booth 2003). Because of their ability to allow water to quickly infiltrate through the surface, permeable pavements allow for reductions in runoff volumes and peak runoff rates, as well as improvements in the water quality of stormwater runoff (Collins et al. 2006).

Stormwater passes through the pervious surface of the permeable pavement, and percolates through the layers of the substructure, where it is temporarily stored. In regions with soils that are highly permeable, the stormwater can be allowed to slowly infiltrate into the native soil (subgrade) underneath the permeable pavement (Collins et al. 2006), whereas in areas with low-permeability soils, effluent water can be conveyed underneath the pavement through an underdrain to a storm sewer system (James and Langsdorff 2003).

\footnotetext{
* Corresponding author: valeo@ucalgary.ca
}

In this paper, the term "permeable pavement" will refer to the entire permeable pavement structure, rather than just the surfacing material (also referred to as the surface course). Several different types of permeable pavement surface courses exist, each with distinguishing physical characteristics. Two such surface courses, and the ones presented in this study, are porous asphalt and open-jointed paving blocks.

Porous asphalt pavement was first developed in the early 1970s and consists of standard bituminous asphalt in which the fines have been screened and reduced, thus creating small voids and allowing water to pass through (Cahill Associates Inc. 2005). Porous asphalt is usually placed directly on a gravel base course.

Open-jointed paving blocks consist of interlocking load-bearing units (often constructed of concrete) that are shaped such that, when laid, they produce open voids between adjacent units. The voids can then be filled with a porous aggregate or turf (Cahill Associates Inc. 2005). It is this fill material that gives the pavement its porosity and permeability (Ferguson 2006). Open-jointed paving blocks are also referred to as permeable unit pavers, modular interlocking concrete blocks with external drainage cells, or permeable interlocking concrete pavers.

Total suspended solids (TSS) is an important pollutant to be removed from stormwater runoff because it is harmful to aquatic ecosystems. It increases water turbidity, inhibits plant growth and diversity, affects river biota, and reduces the overall number of aquatic species. The specific size of solids present is also an important factor, as it may have different impacts on the above mentioned harmful effects. In addition, several pollutants, including certain heavy metals, lead, phosphorus, and 
polycyclic aromatic hydrocarbons tend to be associated with particulate matter, especially finer particles (Balades et al. 1995; Colandini et al. 1995; Legret and Colandini 1999; Environment Australia 2002; Walker and Hurl 2002; Teng and Sansalone 2004). There is currently debate as to what particular size fraction of TSS is the most important to remove from stormwater runoff, but current City of Calgary and Alberta Environment regulations state that $85 \%$ of TSS greater than or equal to 75 microns must be removed on an annual basis (Alberta Environment 2001).

The primary mechanism behind TSS removal is sedimentation and mechanical filtration through the pavement structure (Stotz and Krauth 1994; Urban Water Resources Centre 2002a). Most solids accumulation (and thus removal) has been found to occur in the top several centimetres of the pavement structure (Balades et al. 1995; Pratt et al. 1995; James and Gerrits 2003; James 2004). The geotextile layer above the base course may also play a role in limiting the transport of pollutants into the substructure, and can affect overall filtration efficiency (Pratt et al. 1990; Bond et al. 1999). Effluent from permeable pavements generally has a finer gradation than the influent due to the filtration processes (Legret et al. 1996).

TSS removal efficiency for permeable pavement is highly dependent on the size of particles applied to the pavement surface. Since it acts as a filter, a larger proportion of coarse material will be retained in comparison to fine material. Little research has been done into the analysis of the removal of specific size fractions of TSS by permeable pavements, but it is obviously important to consider the particle size distribution of both influent and effluent when investigating the pavements' capabilities for removing solid matter. Furthermore, as stated previously, the current guidelines for the City of Calgary stipulate a removal rate corresponding to particles over $75 \mu \mathrm{m}$ through stormwater treatment methods. In recent years there has been a debate in the region over the current pollutant loading criteria, and changes in regulations will likely occur in the future. This further increases the need for reliable regional data regarding the capability of permeable pavements for removing various size ranges of particles; these data can then be used to determine the acceptability of these BMPs for whatever future regulations may stipulate.

Therefore, the objectives of this research were to determine the performance of two types of permeable pavements, specifically porous asphalt and open-jointed paving blocks with respect to water quality and fractions of TSS removal. This will help gain a better understanding of the mechanisms and processes behind solids removal within permeable pavement structures. The methodology to do this employed both laboratory models and field installations within an urban development site in the City of Calgary. A discussion of the impacts of clogging on the long-term infiltration capacity of these two types of permeable pavement is described elsewhere (van Duin et al. 2008).

\section{Methodology}

\section{Field Experiments}

Installations. Two pilot-scale permeable pavement installations, with surface courses of porous asphalt and UNI Eco-Stone open-jointed paving blocks, were installed in November 2005 on Hochwald Avenue SW in Calgary, Alberta, Canada (see Fig. 1). The street is a collector road located at Currie Barracks, a former military base, and is used both by local traffic and as a shortcut by residents on either side of Currie Barracks. The site is located directly in front of a stop sign, and the road can be categorized as a low volume road that receives fewer than 1,000 vehicles per day including occasional heavyduty (i.e., Mack truck) vehicles.

Both pavement sections measure approximately $8-\mathrm{m}$ long by $6-\mathrm{m}$ wide, and are on a $3 \%$ longitudinal slope. The porous asphalt surface consists of a $65-\mathrm{mm}$ thick layer of open grade friction course with a maximum aggregate size of 11 to $16 \mathrm{~mm}$ and no particles finer than
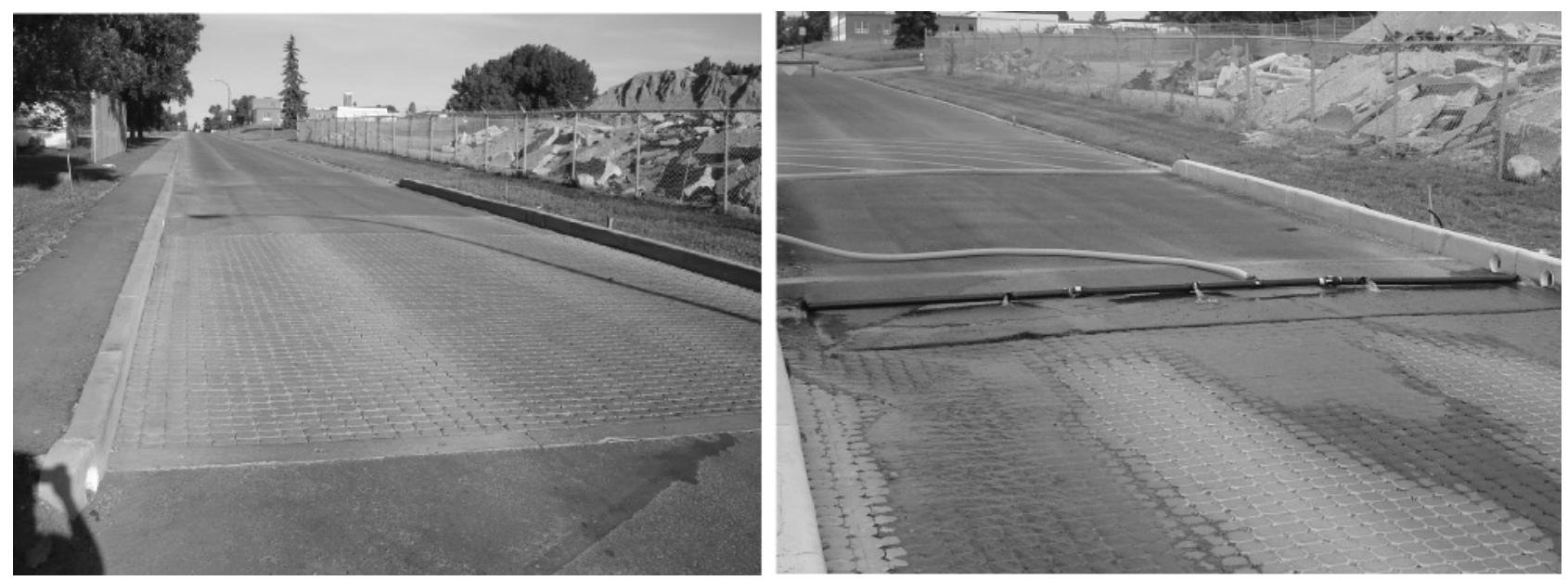

Fig. 1. Currie Barracks permeable pavement installations with field application device shown in right figure (UNI Eco-Stone in foreground, porous asphalt in background). 
$600 \mu \mathrm{m}$. The asphalt has an in-place void space of 18 to $22 \%$ and polymer modified binders and fibers. The UNI Eco-Stone blocks measure 115 by $215 \mathrm{~mm}$, and are 80$\mathrm{mm}$ high, with an overall surface void ratio of $12.18 \%$. Both installations contained a $30-\mathrm{mm}$ bedding course layer beneath the surface course, and a $400-$ to $500-\mathrm{mm}$ base course layer below which was the existing subgrade. Figure 2 details the original design specifications for the Eco-Stone installation, while Fig. 3 shows the gradations of the bedding course layer and base course layer. A Carthage Mills 15\% monofilament woven geotextile separated the bedding course and base course layers, and a nonwoven geotextile separated the base course from the subgrade. A perforated pipe underdrain was situated at the bottom of the base course of both pavements, draining to a nearby monitoring manhole.

At the downstream end of each pavement surface was a concrete pad, running the width of the road, which was used during experiments to seal a wooden beam to the surface in order to replicate ponding water scenarios and to ensure no volume was lost from the experiments.

During the experiments, water was pumped from two water storage tanks to a field runoff applicator (shown in the right image of Fig. 1) fitted with five 2-inch $(5-\mathrm{cm})$ outlets which allowed the water to be dispersed evenly across the width of the pavement. The monitoring equipment located in the monitoring manhole consisted of a V-notch weir, a Hach Sigma 900 autosampler, a Hach Sigma 950 flow meter, and a Hach Sigma $75 \mathrm{KHz}$ ultra sonic flow sensor, which measured the level behind the weir.

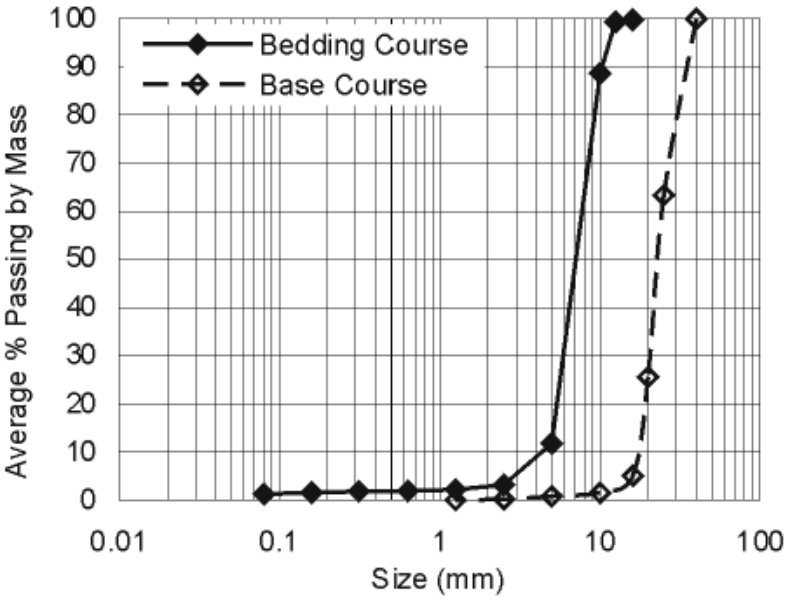

Fig. 3. Gradation analysis of bedding course and base course for Eco-Stone and porous asphalt (and joint fill material for Eco-Stone).

Procedures. The experiments at Currie Barracks consisted of the application of a known volume of water $(8,400 \mathrm{~L})$ to the pavement surfaces at a constant flow rate and with constant TSS concentration $(500 \mathrm{mg} / \mathrm{L})$. Thisconcentration is close to the average event mean concentration recorded by the City of Calgary over multiple storm events. The application water was stormwater hauled from the $69^{\text {th }}$ Street SW storm pond in order to replicate the biological and chemical properties of stormwater runoff, which may play a role in solids and pollutant removal processes

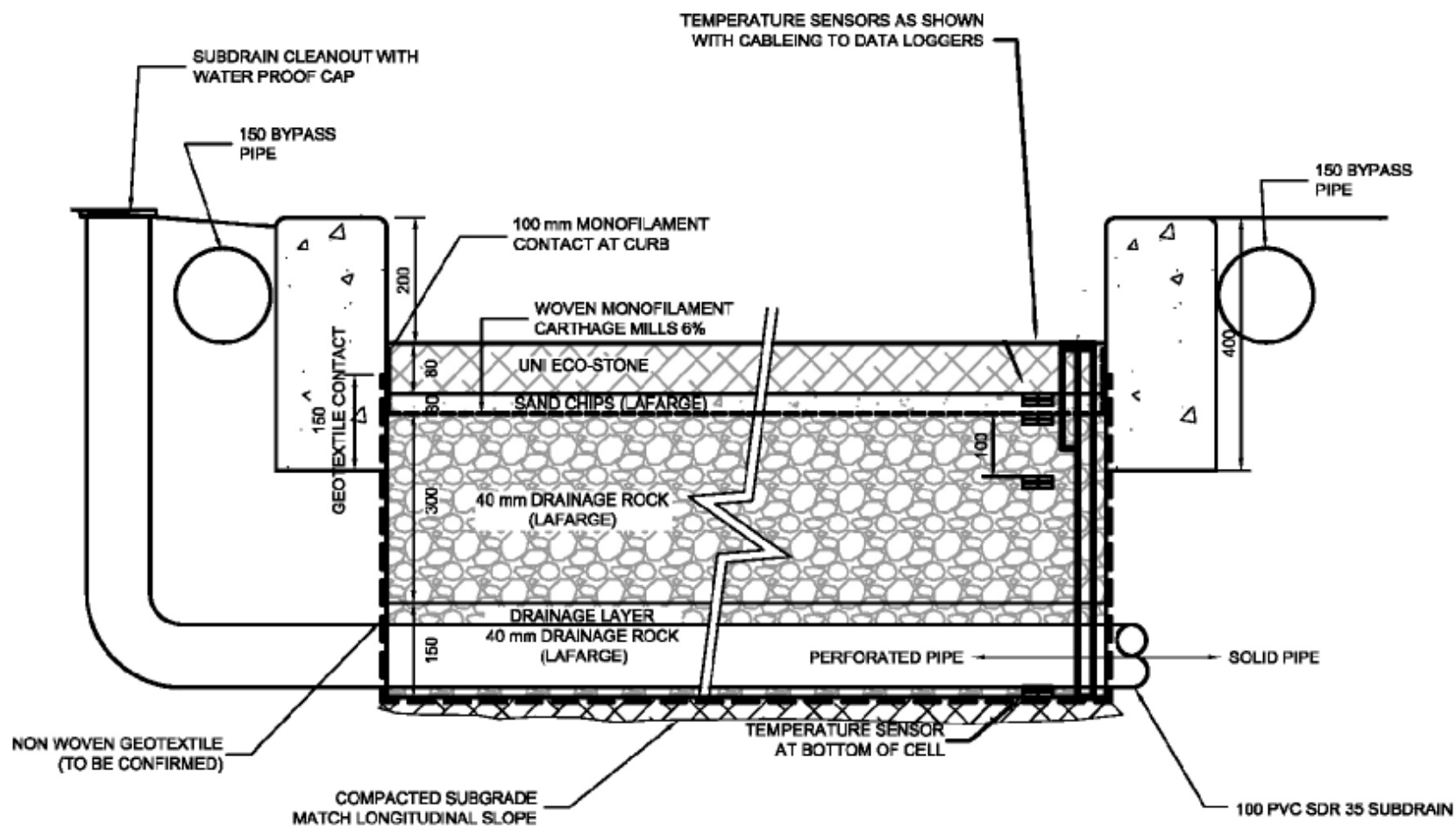

Fig. 2. Currie Barracks permeable pavement cross-section (Eco-Stone installation shown. Porous asphalt installation is identical except for the surface course.) (Courtesy of Westhoff Engineering Resources, Inc.) 
in permeable pavements (Shackel and Pearson 2003). Frequent analysis of the raw stormwater showed the background TSS concentrations averaging between 0 and $10 \mathrm{mg} / \mathrm{L}$; the overall target concentration of $500 \mathrm{mg} / \mathrm{L}$ was not significantly impacted.

Water was pumped from the storage tanks to the pavement surface, at an average flow rate of $5.87 \mathrm{~L} / \mathrm{s}$, which is equivalent to $242 \mathrm{~L} / \mathrm{s} / \mathrm{ha}$ based on a $48.48 \mathrm{~m}^{2}$ pavement surface area and $I / P$ ratio of 4 . The $I / P$ ratio is the impervious to pervious area ratio (dimensionless) for the catchment that the permeable pavement services (Urban Water Resources Centre 2002b). In addition to incident rainfall, permeable pavements may receive runoff from adjacent areas. Thus, consideration must be given to the drainage area upstream of the permeable pavement area. Permeable pavements installed in locations with higher $I / P$ ratios will naturally receive more runoff and thus require higher maintenance than those installed in locations with lower $I / P$ ratios. This factor is often overlooked in the literature when evaluating the performance of permeable pavements in reducing surface runoff. For this study, an $I / P$ ratio of 4 was chosen. This is based on the types of situations in which these pavements could be installed, incorporating the findings from long-term plugging and hydraulic performance research (Urban Water Resources Centre 2002b). The equivalent rainfall intensity for the average $5.87 \mathrm{~L} / \mathrm{s}$ flow rate is about $95 \mathrm{~mm} / \mathrm{hr}$. This is slightly greater than the 1-in-100 year storm event value of approximately $80 \mathrm{~mm} / \mathrm{hr}$ for a 20 minute duration, which is close to the average application time of 23 minutes (The City of Calgary Stormwater Management \& Design Manual 2000). Effluent samples were collected with the Sigma 900 autosampler and, along with manually collected influent samples, were analyzed for TSS and particle size distribution.

\section{Laboratory Models}

Figure 4 shows two lab-scale pavement models used for "long-term" laboratory experimentation of both pavement types. The structures had cross sectional areas of $465 \mathrm{~mm}$ by $465 \mathrm{~mm}$. The layer depths of the pavements for the laboratory models were almost identical to the layers at the field installations with the exception that the base course depth was reduced to $300 \mathrm{~mm}$ in order to minimize the overall weight of the model. There was no geotextile below the base course since effluent collected in an underdrain in a field installation would be above this geotextile. Base effluent readings taken directly after construction of the pavement models, that is, prior to the application of the runoff, amounted to $0 \mathrm{mg} / \mathrm{L}$, verifying the absence of any fines in the aggregate.

Runoff applicators located above the pavement models consisted of an array of 16 vinyl distribution tubes connected to a sheet located approximately 10 $\mathrm{mm}$ above the pavement surfaces. Water was fed into the applicator from a mixing tank which had four mixing blades controlled by a variable speed DC motor capable of keeping large particles (up to $1 \mathrm{~mm}$ ) in suspension.

Experiments and procedures. For this series of experiments, volumes of water with specific concentrations of suspended solids were applied to the pavement models for a simulated period of time. Grab samples for the influent and effluent were frequently taken for TSS and particle size distribution analysis. The following relationship was used to calculate the necessary applied volume for an equivalent simulated year:

$$
V=d A(I / P+1)
$$
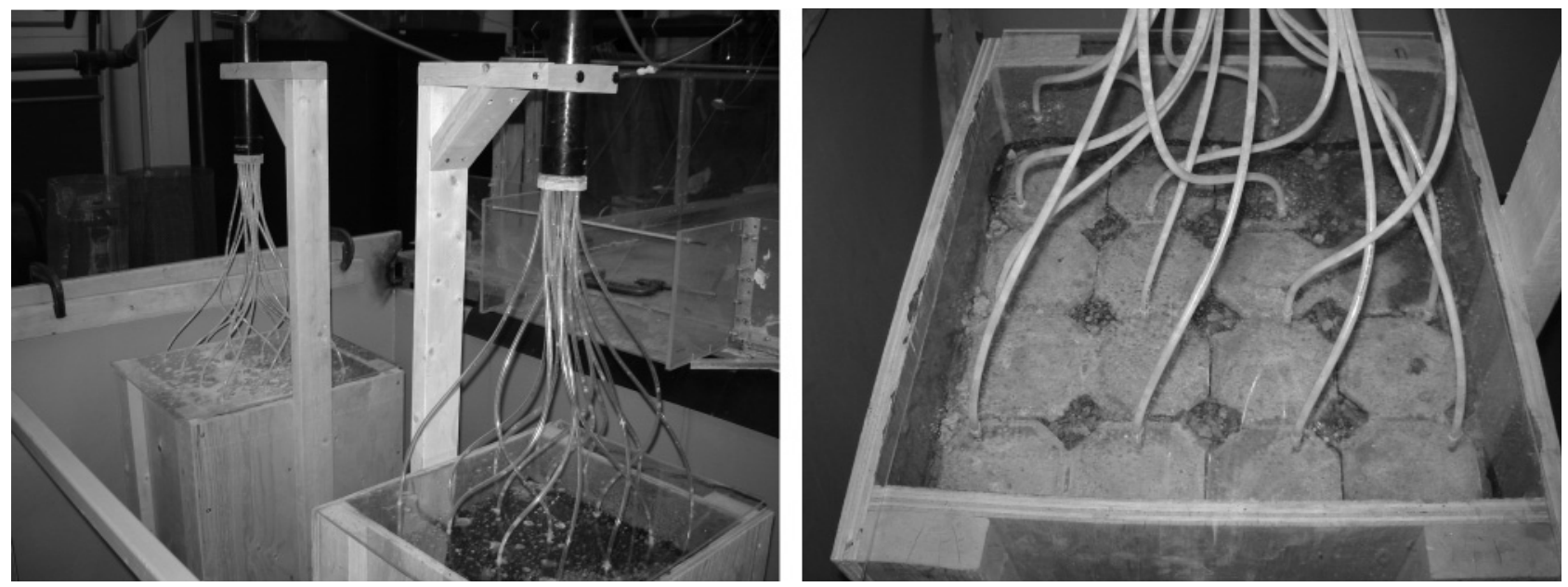

Fig. 4. Laboratory model shown on the left and runoff model detail shown right. 


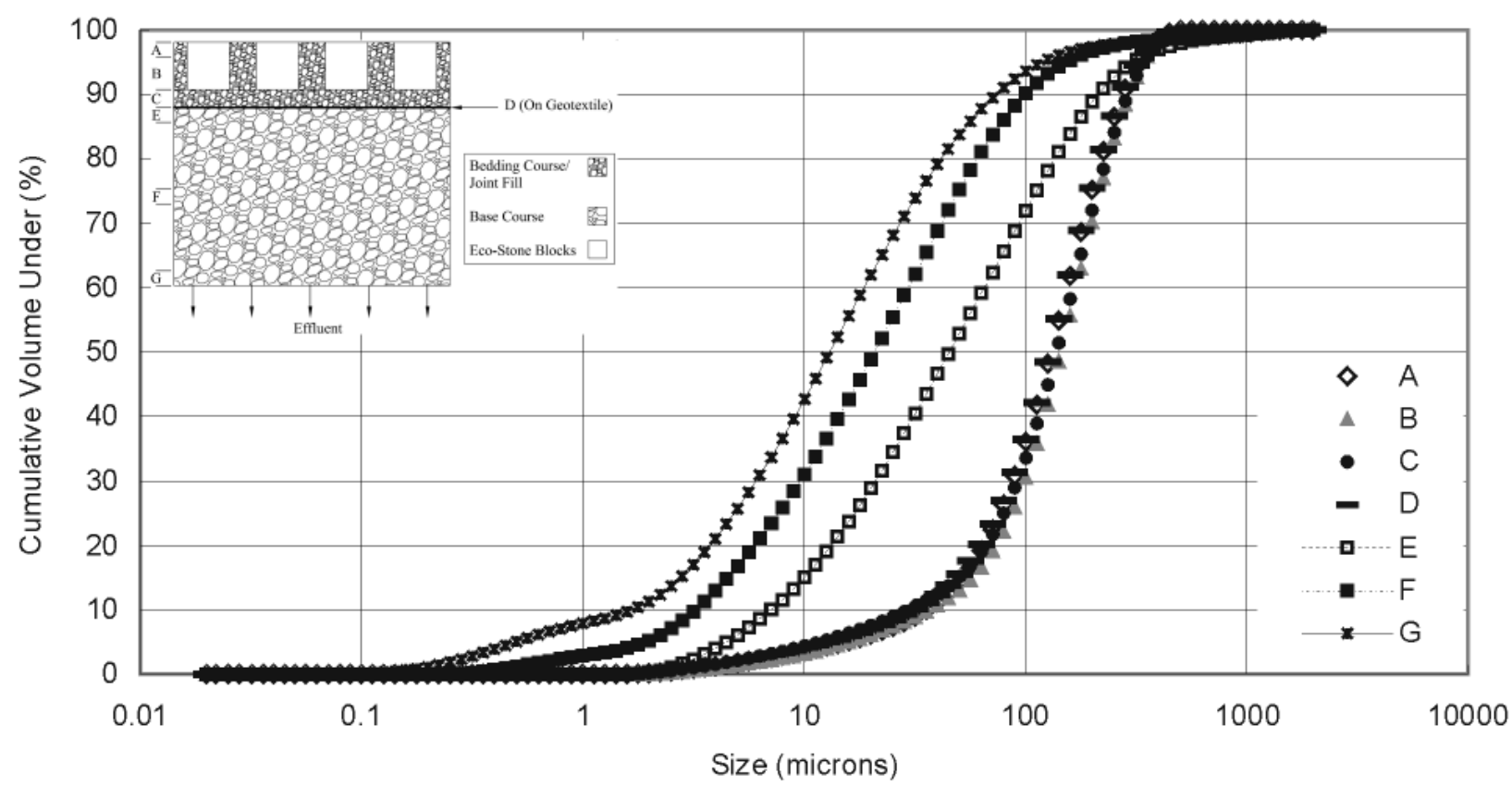

Fig. 5. Particle size distributions for Eco-Stone layers throughout pavement model after simulation of 20 years of runoff (layer locations shown upper left corner).

where $V$ is the equivalent volume of annual precipitation $\left(\mathrm{m}^{3}\right), d$ is the average annual depth of precipitation in Calgary $(\mathrm{m}), A$ is the permeable pavement area $\left(\mathrm{m}^{2}\right)$; and $I / P$ is the impervious to pervious area ratio (dimensionless).

For the pavement models, the total surface area was $0.216 \mathrm{~m}^{2}$, the average annual precipitation for Calgary was approximately $400 \mathrm{~mm}$, and an $I / P$ ratio of 4 was assumed. Therefore, the application of approximately $0.432 \mathrm{~m}^{3}$, or $432 \mathrm{~L}$ of water (rounded down to $425 \mathrm{~L}$ for sake of simplicity), loaded with $500 \mathrm{mg} / \mathrm{L}$ of sediment, was required to simulate one year of stormwater runoff for each laboratory model.

Water from the mixing tank was applied continuously to the runoff applicators for both pavement models at the same flow rate of $0.009 \mathrm{~L} / \mathrm{s}$. A total of 20 years' runoff and sediment application was simulated for both pavement types to replicate the long-term performance of the two pavement structures. Upon completion of the 20-year simulated application, the pavement models were carefully disassembled, and samples of accumulated sediment were collected from various layers of both pavement models so that the particle size distribution could be analyzed throughout the structures.

For the Eco-Stone model, sediment was collected from the top $25 \mathrm{~mm}$ of joint fill material (Location $\mathrm{A}$ as shown in insert of Fig. 5); the bottom $55 \mathrm{~mm}$ of joint fill material (Location $\mathrm{B}$ ); the bedding course (Location $\mathrm{C}$ ); on top of the geotextile (Location D); and three separate depths of the base course (Locations E, F, and G). For the porous asphalt model, samples were collected from the asphalt surface itself (Location A as shown in insert of Fig. 6); the bedding course (Location B); on top of the geotextile (Location $\mathrm{C}$ ); and from three separate depths of the base course (Locations D, E, and F).

\section{Sediment Characteristics}

Experiments were performed with sediment collected from Calgary roads in order to observe realistic longterm performance of the pavement structures. Spring cleaning street sweepings from the City of Calgary were collected and sieved to a size of $250 \mu \mathrm{m}$ and below.

The sediment was sieved to $250 \mu \mathrm{m}$ because this represents the finer portion of material that would typically be found on Calgary streets. The finer portion was desired since this is typically the material that is ultimately responsible for the clogging of permeable pavements (Gerrits 2001). With regards to filtration capabilities, it is presumed that if the pavements are capable of removing the sub-250- $\mu \mathrm{m}$ particles, they would be capable of removing larger particles as well. It is also the size range that is of particular importance in stormwater treatment because of its association with particular pollutants and the relative ease with which it can be mobilized and transported into stormwater discharges (Barnes et al. 2001). Research has shown that finer particulates $(<250 \mu \mathrm{m})$ are more efficient in the adsorption of pollutants, including phosphates, heavy metals, and pesticides, and as such will carry a higher pollutant concentration (Sartor et al. 1974; Roger et al. 1998; Andral 1999).

For both field and laboratory experiments, the same $500 \mathrm{mg} / \mathrm{L}$ concentration of sediment was applied to the 


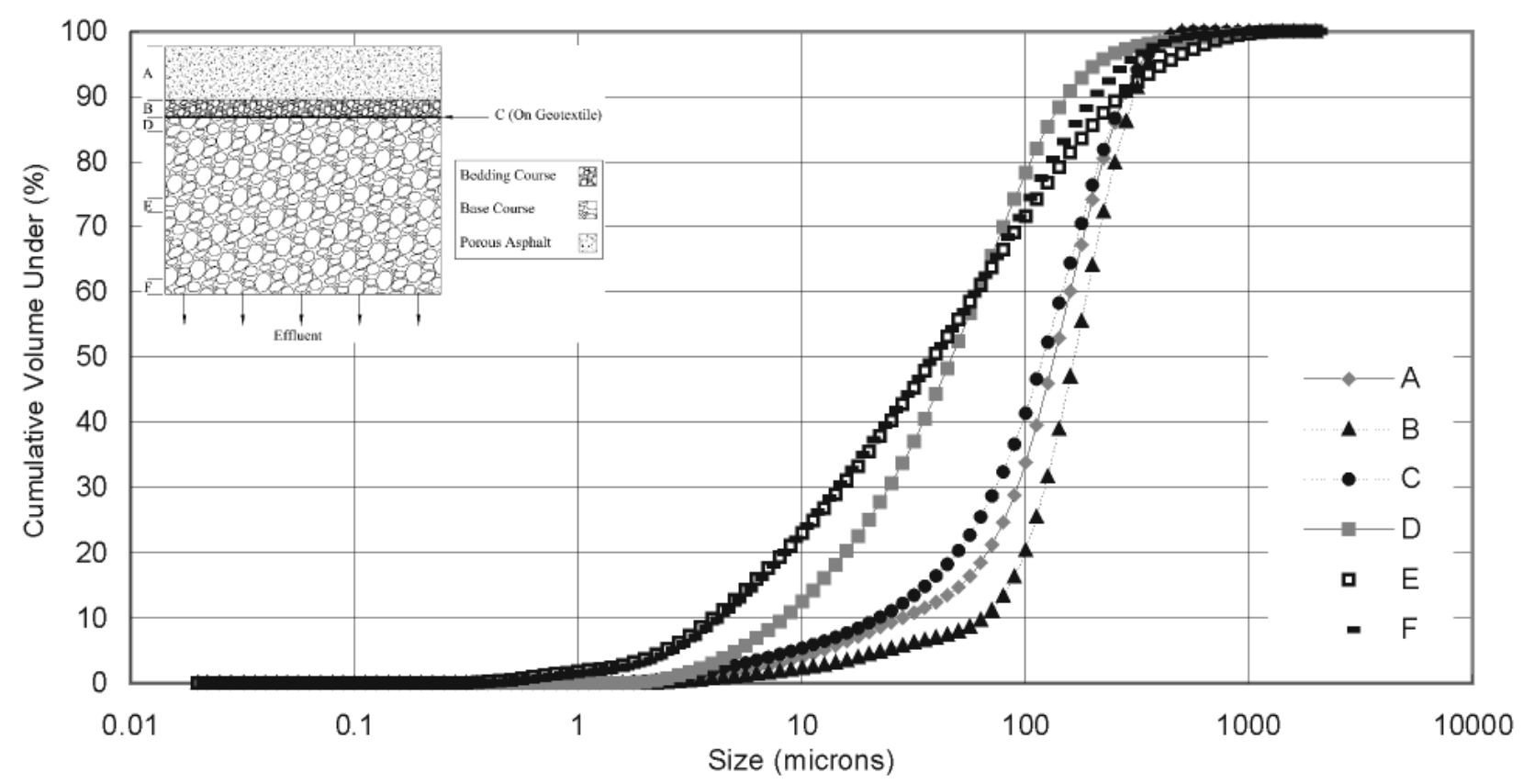

Fig. 6. Particle size distributions for porous asphalt layers throughout pavement model after simulation of 20 years of runoff (layer locations shown upper left corner).

surfaces, and grab samples of inflow concentration were taken consistently throughout all experimental runs. Due to turbulence within the mixing tank, the instantaneous TSS concentration of the inflow varied considerably. However, the overall average over the course of experiments remained $500 \mathrm{mg} / \mathrm{L}$.

For the field experiments, the sediment was applied manually to the pavement surface by, as evenly as possible, dispersing $500 \mathrm{~g}$ of sediment over the pavement for every 1,000 L of continuously applied water from the storage tanks through the field runoff applicator. The sediment was applied in this manner because it proved too difficult to keep the sediment in suspension in the field experiments. There can be inconsistencies in the instantaneous concentrations of the applied water, however, given that the experiments at Currie Barracks represent ponding situations, the average concentration of water infiltrating the pavements, or the event mean concentration, would have been very close to $500 \mathrm{mg} / \mathrm{L}$. The influent particle size distributions (PSDs) were taken by collecting 2-L samples at the outlets of the conveyance tubes, centrifuging, and collecting the sediment.

The washed bedding course and base course materials did not contain any particles finer than $500 \mu \mathrm{m}$, and the applied sediment was all passed through a $250-\mu \mathrm{m}$ sieve. Consequently, the sediment at the various layers of the pavement structures was obtained by gently washing the aggregate from each location through a $500-\mu \mathrm{m}$ sieve and collecting the wash water and sediment from beneath the sieve. All accumulated street sweepings sediment passed through the sieve, while any material from the courses within the pavement structures themselves was retained on the sieve. The collected samples were then centrifuged, separated, and analyzed.

\section{Analytical Methods for TSS}

TSS was analyzed according to the procedures described in Standard Methods for the Examination of Water and Wastewater (APHA et al. 1999). Particle size analysis was performed with a Malvern Mastersizer 2000 laser diffraction particle size analyzer. A bulk sample of approximately 0.5 to 1 gram of sediment was required for an accurate analysis using the laser diffraction analyzer. To collect this mass of sediment, a considerable volume of effluent was required, in some cases more than $10 \mathrm{~L}$. This liquid sample was centrifuged at 4,000 rpm for 15 minutes in four 1-L bottles per cycle. After removal from the centrifuge, the liquid supernatant was poured off, and the sludge was removed using a spoon. Once the sediment had been collected, it was dried and separated into the appropriate target mass of 0.1 to 0.3 grams. This 0.1 to 0.3 gram subsample was then soaked overnight in hydrogen peroxide (concentration of $30 \%$ ) to dissolve organic bonds and allow better separation of particles. This naturally dissolves a portion of the organic content, but for low-organic-content samples such as those used in this study, removal of the organic content was not believed to have a significant impact on the particle size distribution. Following this, the sample was soaked overnight in Calgon to properly disperse the particles, at which point it was ready for analysis in the Malvern Mastersizer 2000. 


\section{Results and Discussion}

\section{TSS Removal Characteristics Observed in the Field Experiments}

Both pavement surface types displayed very similar TSS removal efficiencies, with 92 to $98 \%$ of applied TSS removed from the simulated runoff influent. Figure 7 shows the particle size distributions of the influent and effluent at Currie Barracks for the Eco-Stone and porous asphalt pavements. These are averages of the results for all the dates when simulated runoff experiments were performed. For the Eco-Stone, the maximum and minimum standard deviations of the influent results for all the run dates and all particle sizes were 8.6 and $1.2 \%$, respectively. For the Eco-Stone effluent, the maximum and minimum standard deviations were 11.0 and $4.3 \%$, respectively. The corresponding maximum and minimum standard deviations for the porous asphalt influent and effluent were 4.7 and $1.1 \%$, and 7.1 and $3.0 \%$, respectively. Substantially finer solids were observed in the effluent as compared with the influent. The effluent PSD did not appear to show any consistent patterns of change over the course of a single experiment, or from experiment to experiment.

Based on average particle size distribution data for all experimental dates, and overall average TSS removal rates for a particular pavement, one can arrive at approximations of removal efficiency for various size fractions within the pavement. The formulas used to calculate removal efficiency of particular size fractions are as follows:

$$
\begin{aligned}
\beta_{\leq x} & =\frac{T S S_{i n(\leq x)}-T S S_{e f f(\leq x)}}{T S S_{i n(\leq x)}} \\
& =\frac{T S S_{i n} \alpha_{i n}-T S S_{e f f} \alpha_{e f f}}{T S S_{i n} \alpha_{i n}} \\
& =\frac{T S S_{i n} \alpha_{i n}-(1-\xi) T S S_{i n} \alpha_{e f f}}{T S S_{i n} \alpha_{i n}} \\
& =\frac{\alpha_{i n}-\left[(1-\xi) \alpha_{e f f}\right]}{\alpha_{i n}}
\end{aligned}
$$

where $\beta_{\leq x}$ is the removal efficiency for all particles less than or equal to $X \mu \mathrm{m}$; TSS $i n(\leq x)$ is the TSS in the influent less than or equal to $X \mu \mathrm{m}(\mathrm{mg} / \mathrm{L})$; TSS $_{\text {eff( }(x)}$ is the TSS in the effluent less than or equal to $X \mu \mathrm{m}(\mathrm{mg} / \mathrm{L}) ; T^{2} S_{i n}$ is the TSS in the influent (total, $\mathrm{mg} / \mathrm{L}$ ); $\alpha_{i n}$ is the proportion of influent that is less than or equal to $X \mu \mathrm{m}$; TSS ${ }_{e f f}$ is the TSS in the effluent (total, $\mathrm{mg} / \mathrm{L}$ ); $\alpha_{\text {eff }}$ is the proportion of effluent that is less than or equal to $X \mu \mathrm{m}$; and $\xi$ is the average overall removal efficiency of all TSS.

Similarly,

$$
\begin{aligned}
\beta_{\geq x} & =\frac{T S S_{i n(\geq x)}-T S S_{e f f(\geq x)}}{T S S_{i n(\geq x)}} \\
& =\frac{T S S_{i n}\left(1-\alpha_{i n}\right)-T S S_{e f f}\left(1-\alpha_{e f f}\right)}{T S S_{i n}\left(1-\alpha_{i n}\right)} \\
& =\frac{T S S_{i n}\left(1-\alpha_{i n}\right)-(1-\xi) T S S_{i n}\left(1-\alpha_{e f f}\right)}{T S S_{i n}\left(1-\alpha_{i n}\right)} \\
& =\frac{\left(1-\alpha_{i n}\right)-\left[(1-\xi)\left(1-\alpha_{e f f}\right)\right]}{\left(1-\alpha_{i n}\right)}
\end{aligned}
$$

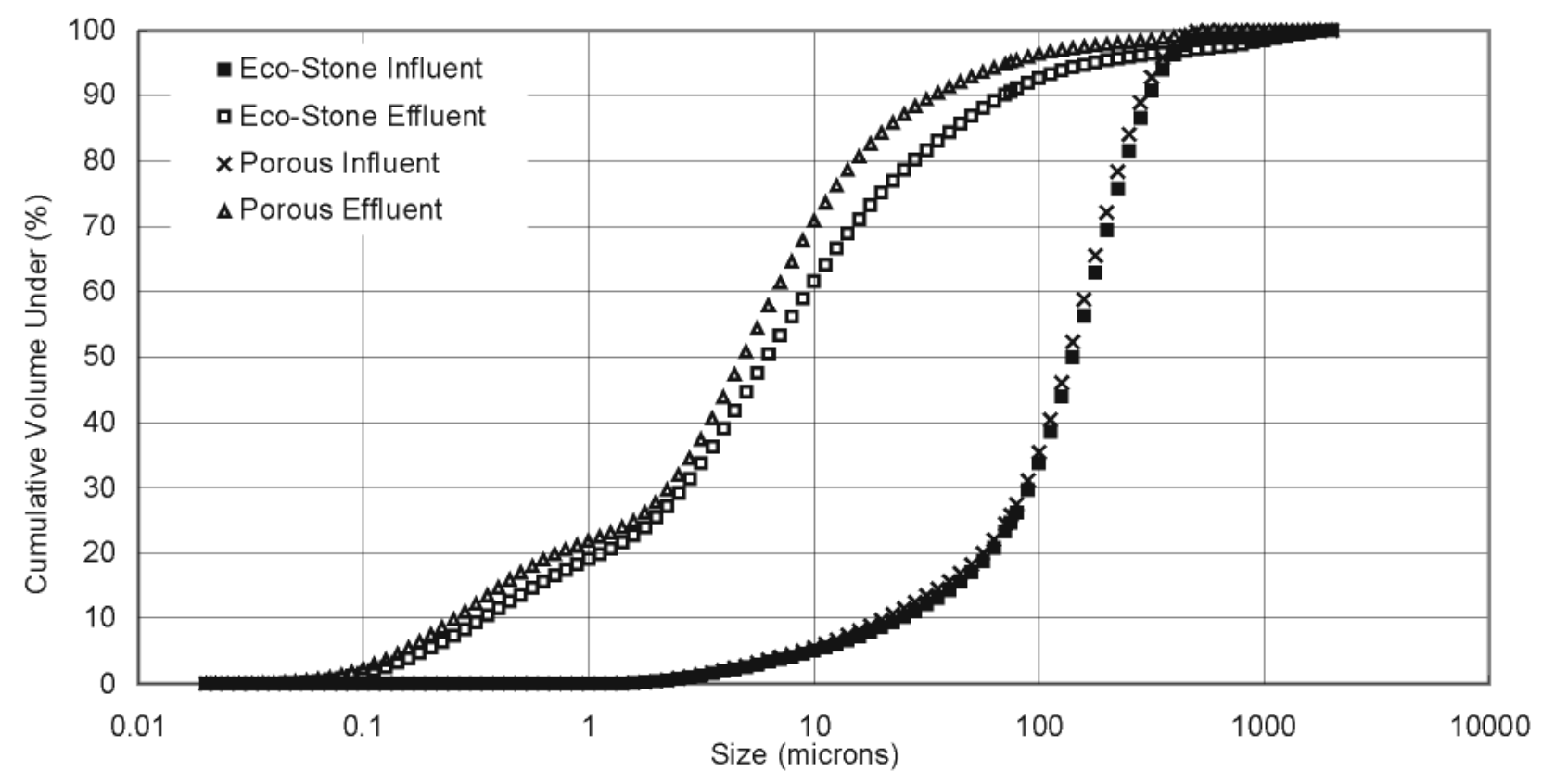

Fig. 7. Average particle size distributions at Currie Barracks. 
where $\beta_{2 x}$ is the removal efficiency for all particles greater than or equal to $X \mu \mathrm{m}$; TSS $S_{i n(x)}$ is the TSS in the influent greater than or equal to $X \mu \mathrm{m}(\mathrm{mg} / \mathrm{L})$; and $T S S_{e f f(x)}$ is the TSS in the effluent greater than or equal to $X \mu \mathrm{m}$ $(\mathrm{mg} / \mathrm{L})$.

The calculated removal efficiencies are shown in Table 1 for particle size fractions above and below 200, $100,75,50,25$, and $10 \mu \mathrm{m}$ for both pavement types. It is emphasized that these fractional removal efficiencies are valid only for the specific influent that was used in these simulated experiments. If an influent with a different PSD were applied to the pavements, the removal efficiencies for the various size fractions would vary accordingly.

Of particular importance, from the perspective of stormwater treatment in Calgary, are the particles over $75 \mu \mathrm{m}$. As shown in Table 1, the removal efficiency for particles greater than or equal to $75 \mu \mathrm{m}$ is above $99 \%$ for both pavement types for this particular type of sub$250-\mu \mathrm{m}$ street sweeping influent. For particles finer than $75 \mu \mathrm{m}$, the removal rates are $74 \%$ for the Eco-Stone and $83 \%$ for the porous asphalt. As the size range decreases from $75 \mu \mathrm{m}$, the removal rate begins to drop drastically for both pavement types. From a water quality standpoint, the performance of both pavement types in this study for removing solids is exceptional. Again, it must be stressed that these values are only valid for the influent used for this study. For future studies it would be very informative to apply influents with different PSDs and observe the changes in removal efficiencies for various influent size ranges.

\section{TSS Removal Characteristics Observed in the Laboratory Experiments}

The long-term effluent TSS concentrations for both pavements are shown in Fig. 8. Removal efficiencies for both surface types were $96 \%$ averaged over 100 data points, and with standard deviations of 2.8 and $3.6 \%$ for the Eco-Stone and porous asphalt models, respectively.

The particle size distributions of the influent and effluent for the laboratory Eco-Stone and porous asphalt models are shown in Fig. 9. The effluent particle size

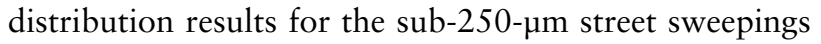
were very similar for both pavement types, and were also very similar for the laboratory and field experiments at Currie Barracks. The fractional removal efficiencies for the laboratory installations are shown in Table 2. The results are very similar to those observed in the field installations. Again, the removal efficiency decreased for the finer fractions.

For fractional removal efficiencies in the very fine range (i.e., $<10 \mu \mathrm{m}$ ), the accuracy of this method becomes questionable. To illustrate the reason behind this, consider that, in the influent, there were consistently zero particles detected below $1 \mu \mathrm{m}$, whereas for the effluent, the average fraction below $1 \mu \mathrm{m}$ was as high as $25 \%$. It would appear as though fines, which were not present in the influent, are appearing in the effluent. The reason for this apparent slight discrepancy for small particle sizes is due to the precision of the PSD analyzer. The effluent was much finer than the influent, and was also only $5 \%$ of the influent concentration. Therefore, very fine elements that may have been obscured due to very low absolute quantities of particles in the influent, were observed in the effluent because of an "amplification effect" of the finer particles. The particles were present in the influent, but they were in such minute quantities that they were below the detectable limits of the analyzer, or otherwise obscured due to low particle numbers.

TABLE 1. Particle size fractional removal efficiencies for the Eco-Stone and porous asphalt installations at Currie Barracks ${ }^{a, b}$

\begin{tabular}{lccccc}
\hline $\begin{array}{l}\text { Size } \\
\text { fraction } \\
(\boldsymbol{\mu} m)\end{array}$ & $\begin{array}{c}\text { Proportion of } \\
\text { influent under } \\
\text { size fraction } \\
(\%)\end{array}$ & $\begin{array}{c}\text { Standard } \\
\text { deviation } \\
(\%)\end{array}$ & $\begin{array}{c}\text { Proportion of } \\
\text { effluent under } \\
\text { size fraction } \\
(\%)\end{array}$ & $\begin{array}{c}\text { Standard } \\
\text { deviation } \\
(\%)\end{array}$ & $\begin{array}{c}\text { \% Removal } \\
\text { for } \\
\text { size fraction }\end{array}$ \\
\hline$>200$ & $30.5(27.8)$ & $8.2(4.5)$ & $4.5(2.1)$ & $2.6(1.2)$ & 99 \\
$>100$ & $66.2(64.6)$ & $5.2(3.8)$ & $7.1(3.6)$ & $2.8(2.4)$ & 99 \\
$>75$ & $75.4(74.2)$ & $2.5(3.9)$ & $9.0(4.8)$ & $3.1(3.5)$ & 99 \\
$>50$ & $82.9(81.7)$ & $1.3(4.2)$ & $12.5(7.1)$ & $3.7(5.1)$ & 99 \\
$>25$ & $89.8(88.4)$ & $0.9(2.7)$ & $20.7(12.8)$ & $4.8(6.9)$ & $98(99)$ \\
$>10$ & $94.9(94.5)$ & $0.2(0.8)$ & $37.8(29.2)$ & $7.8(6.6)$ & $97(97)$ \\
$<200$ & $69.5(72.2)$ & $8.2(4.5)$ & $95.4(97.9)$ & $2.6(1.2)$ & $90(94)$ \\
$<100$ & $33.8(35.4)$ & $5.2(3.8)$ & $93.3(96.4)$ & $2.8(2.4)$ & $80(87)$ \\
$<75$ & $24.6(25.8)$ & $2.5(3.9)$ & $91.0(95.2)$ & $3.1(3.5)$ & $74(83)$ \\
$<50$ & $17.1(18.3)$ & $1.3(4.2)$ & $87.5(92.9)$ & $3.7(5.1)$ & $64(76)$ \\
$<25$ & $10.3(11.5)$ & $0.9(2.7)$ & $79.3(87.2)$ & $4.8(6.9)$ & $45(64)$ \\
$<10$ & $5.1(5.5)$ & $0.2(0.8)$ & $62.2(70.9)$ & $7.8(6.6)$ & $13(40)$ \\
\hline
\end{tabular}

${ }^{a}$ Porous asphalt numbers are shown in parenthesis after the Eco-Stone numbers.

${ }^{b}$ Similar numbers are not repeated. 
Equivalent Simulated $Y$ ears for I/P $=4$

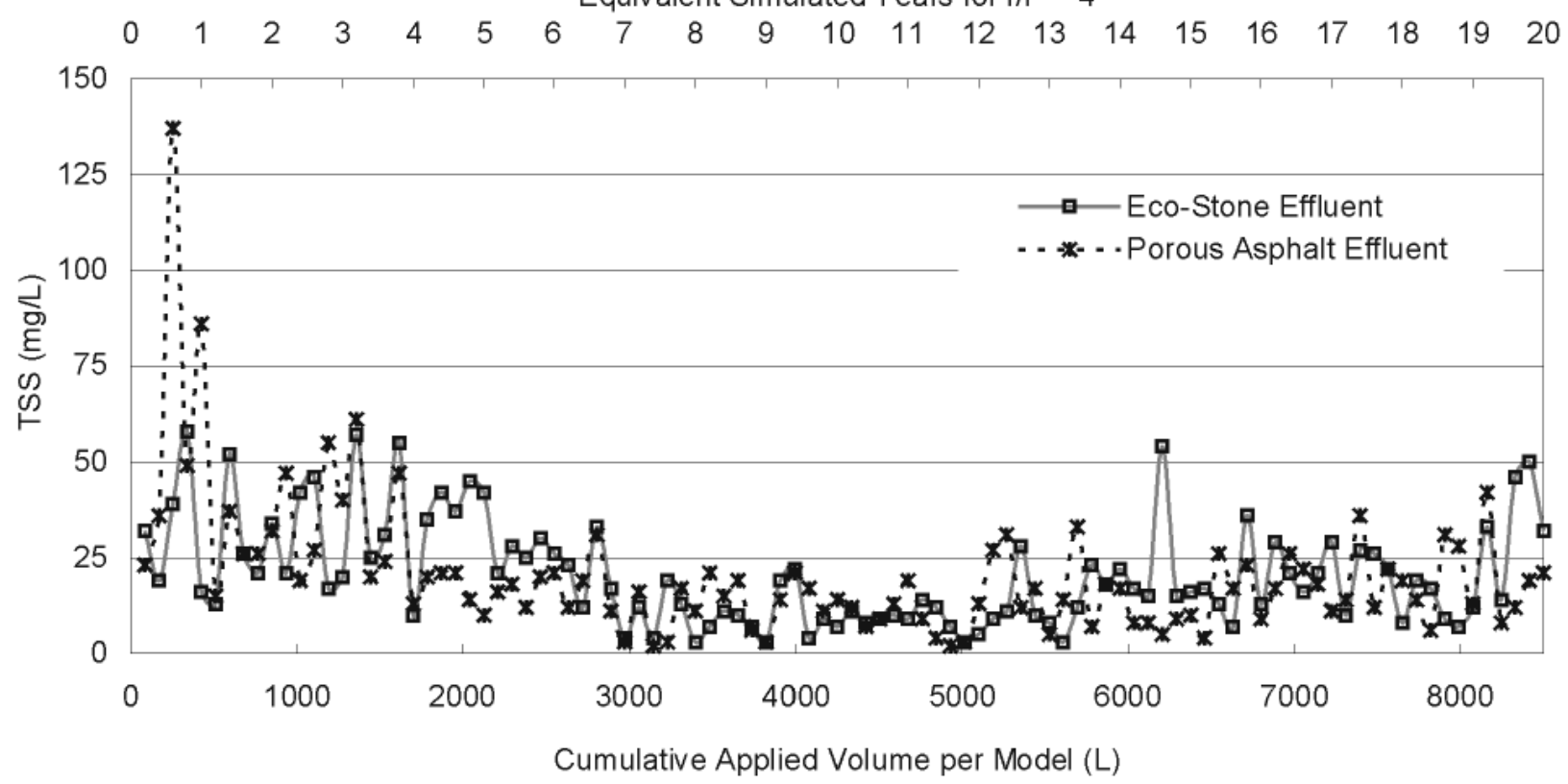

Fig. 8. Long-term effluent TSS for Eco-Stone and porous asphalt.

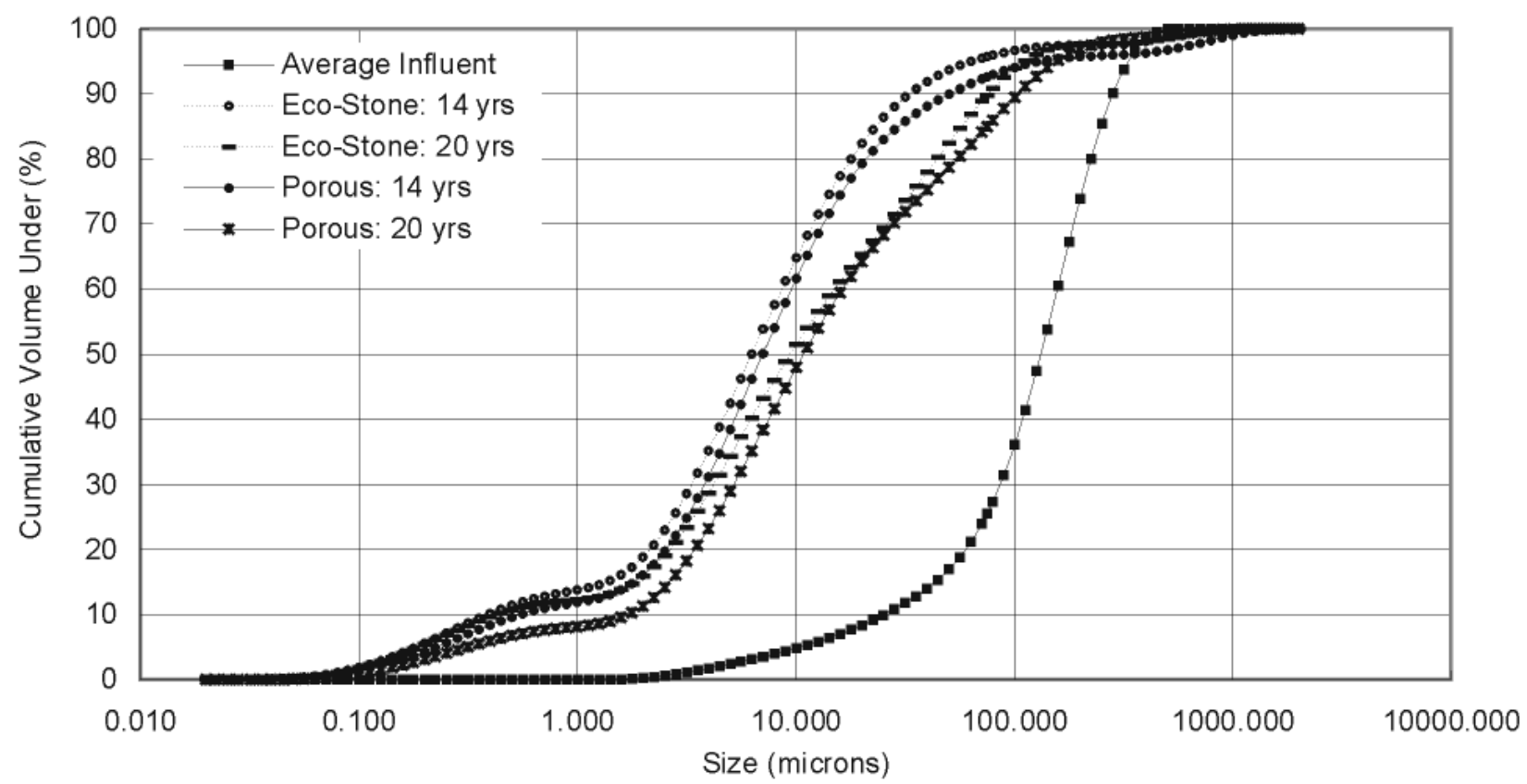

Fig. 9. Particle size distribution for the influent and effluent for long-term laboratory simulation for sub-250- $\mu \mathrm{m}$ street sweepings. 
TABLE 2. Particle size fractional removal efficiencies for the Eco-Stone and porous asphalt models for the long-term laboratory simulations

\begin{tabular}{lccccc}
\hline $\begin{array}{l}\text { Size } \\
\text { fraction } \\
(\boldsymbol{\mu} m)\end{array}$ & $\begin{array}{c}\text { Proportion of } \\
\text { influent under } \\
\text { size fraction } \\
(\%)\end{array}$ & $\begin{array}{c}\text { Standard } \\
\text { deviation } \\
(\%)\end{array}$ & $\begin{array}{c}\text { Proportion of } \\
\text { effluent under } \\
\text { size fraction } \\
(\%)\end{array}$ & $\begin{array}{c}\text { Standard } \\
\text { deviation } \\
(\%)\end{array}$ & $\begin{array}{c}\text { \% Removal } \\
\text { for } \\
\text { size fraction }\end{array}$ \\
\hline$>200$ & 24.7 & 3.9 & $3.8(4.3)$ & $2.7(2.2)$ & 99 \\
$>100$ & 62.0 & 3.8 & 7.1 & 2.5 & 99 \\
$>75$ & 72.9 & 3.3 & $7.7(9.0)$ & $3.6(2.1)$ & 99 \\
$>50$ & 82.2 & 2.8 & $11.1(12.3)$ & $4.8(4.2)$ & 99 \\
$>25$ & 89.8 & 1.4 & $20.1(20.7)$ & $7.2(6.2)$ & 99 \\
$>10$ & 95.1 & 0.4 & $41.0(42.3)$ & $8.5(9.0)$ & 98 \\
$<200$ & 75.3 & 3.9 & $96.2(95.7)$ & $2.7(2.2)$ & 95 \\
$<100$ & 38.0 & 3.8 & 92.9 & 2.5 & 90 \\
$<75$ & 27.1 & 3.3 & $92.3(91.0)$ & $3.6(3.1)$ & 86 \\
$<50$ & 17.8 & 2.8 & $88.9(87.7)$ & $4.8(4.2)$ & $79(80)$ \\
$<25$ & 10.2 & 1.4 & $79.9(79.3)$ & $7.2(6.2)$ & 68 \\
$<10$ & 4.9 & 0.4 & $59.1(57.7)$ & $8.5(9.0)$ & $51(52)$ \\
\hline
\end{tabular}

${ }^{a}$ Porous asphalt numbers are shown in parenthesis after the Eco-Stone numbers.

${ }^{b}$ Similar numbers are not repeated.

\section{Size Distribution of Particle Accumulation Throughout the Structure}

For the laboratory experiments, Fig. 5 and 6 show the results for the PSD analyses of the various layers of the pavement models, with the layer locations shown in the upper corner of the figures. For both pavement models, the layers above the geotextile appear to have very little influence on the sieving of specific particle sizes, while the geotextile itself appears to be most influential. The PSD of the sediment changes very little through the surface course and bedding course, although it is followed by a relatively drastic change above and below the geotextile (Locations D and E for Fig. 5, and Locations C and D for Fig. 6). The material is substantially finer below the geotextile as compared with the material above the geotextile. Interestingly, there also appears to be a change from the top to the bottom of the base course material. Regardless, these findings are significant in that they demonstrate the role the geotextile can have in filtration for permeable pavements.

At the time of this study, the literature contained very few studies that examined the particle sizes removed in permeable pavements and exactly where in the pavement structure those particles were being removed. The literature contains many studies discussing total efficiency of TSS removal, but these studies did not focus on the influent composition and the effluent PSD. Furthermore, there is very little information on the longterm performance of these pavement structures due to costs and wait periods associated with long-term studies. The lab experiments were an attempt to circumvent the long time periods, but to still gain a relatively good idea of long-term performance. Thus, the laboratory studies complemented the field studies; however, as with any laboratory study, the utility of the results depends on how well the real-world conditions leading to clogging and solids removal were simulated in the laboratory. The capacity for particles to pass through the upper layers of the pavement decreases slowly and progressively with time as finer and finer particles are trapped until a relatively impermeable matrix (or "crust") is formed (Balades et al. 1995; James and Gerrits. 2003; James 2004). This "clogged" area is usually limited to the upper few centimetres of the surface structure (Balades et al. 1995; Pratt et al. 1995; James and Gerrits 2003; James 2004) and is therefore characterized by an increase in the quantity of material retained in the upper surface, and not necessarily by migration of sediment particles to the subsurface layers of the structure (Balades et al. 1995). The laboratory experiments did not mimic the wetting and drying cycles and vehicular traffic impacts that create conditions leading to the formation of that crust; however, the overall removal performance was comparable. In addition, oil and grease effects were not incorporated in the laboratory model. Oil and grease have been shown to contribute to reductions in infiltration capacity with age (Gerrits 2001) and thus, possible differences between the laboratory and field results may be attributed to the lack of oil/grease in the laboratory models. The inclusion of these effects was beyond the scope of this study. While greater work is needed to improve the representativeness of the lab experiments, the approach described in this paper allows for further optimization of the composition of the pavement structure in future studies, especially when combined with optimizing the long-term hydraulic performance of these types of pavement structures.

\section{Conclusions and Recommendations}

The primary objectives of this research were to determine the performance of two types of permeable pavement with respect to hydraulics and water quality, and to try to gain a better understanding of the mechanisms and processes behind solids removal and clogging within permeable pavement structures. Results demonstrated 
that both permeable pavement types exhibited excellent TSS removal efficiencies both in laboratory and field settings, typically ranging from 90 to $96 \%$. The effluent was found to be considerably finer than the influent, and the "sieving action" in a laboratory setting was found to occur most predominantly at the geotextile layer. This is somewhat contradictory to the findings of other studies (Balades et al. 1995; Pratt et al. 1995; James and Gerrits 2003; James 2004) in which filtration primarily took place at the surface of the pavement; this may be due to the influent characteristics and the lack of "crust" formation in the laboratory as it was not feasible to replicate the wetting and drying cycles and vehicular traffic impacts in the laboratory experiments. The findings in this study are significant in that they highlight the potential of being able to optimize the composition of the pavement structure by choosing appropriate materials and locations for the various courses and geotextiles in the pavement. Furthermore, $99 \%$ of particles sized 75 microns and over were removed by these particular pavement structures, whereas 74 to $86 \%$ of particles under 75 microns were removed. These fractional removal efficiencies are true only for the sub-250- $\mu \mathrm{m}$ sediment used in this study. Nonetheless, they show that the pavements meet current City of Calgary TSS removal guidelines.

Recommendations for future research include studies on the effects of influent TSS concentration on overall TSS removal rates and on fractional solids removal efficiencies of these pavement structures using a variety of influent sediments, with multiple particle size distributions.

Experiments examining the influences of different joint fill and bedding materials, as well as different geotextiles, and geotextile locations throughout the pavement structure, may provide more insight into what combination provides the best balance between solids removal and long-term hydraulic performance. Finally, realistic methods to simulate the wetting and drying cycles and the motion and impact of vehicular traffic are recommended as they would allow more representative long-term laboratory experiments to be performed.

\section{Acknowledgments}

The authors wish to express their gratitude to Canada Lands Company, NSERC, the University of Calgary, the City of Calgary, and Westhoff Engineering Resources, Inc. for providing both technical and financial support for this project. The authors would also like to thank Lynne Cowe-Falls, Schulich School of Engineering of the University of Calgary for her assistance.

\section{References}

Alberta Environment. 2001. Municipal Policies and Procedures Manual. Alberta Environment, Edmonton, AB. Available on-line at: http://environment.gov.ab.ca/info/library/7278.pdf. [Accessed: March 1, 2008].
Andral MC. 1999. Particle size distribution and hydrodynamic characteristics of solid matter carried by runoff from motorways. Water Environ. Res. 71(4):398-407.

APHA, AWWA, WEF. 1999. Standard methods for the examination of water and wastewater. $20^{\text {th }}$ Edition. Published jointly by the American Public Health Association, American Water Works Association, and Water Environment Federation. New York.

Balades JD, Legret M, Madiec H. 1995. Permeable pavements: Pollution management tools. Water Sci. Technol. 32(1):49-56.

Barnes KB, Morgan III JM, Roberge MC. 2001. Impervious surfaces and the quality of natural and built environments. Towson University, Baltimore.

Bond PC, Pratt CJ, Newman AP. 1999. A review of stormwater quantity and quality performance of permeable pavements in the UK. In 8th International Conference on Urban Storm Drainage. Sydney, Australia.

Brattebo BO, Booth DB. 2003. Long-term stormwater quantity and quality performance of permeable pavement systems. Water Res. 37(18):4369-4376.

Cahill Associates Inc. 2005. Comprehensive stormwater management: Structural BMPs. Pennsylvania stormwater best management practices manual 2nd draft, p. 197-276. West Chester, PA.

Colandini V, Legret M, Brosseaud Y, Balades JD. 1995. Metallic pollution in clogging materials of urban porous pavements. Water Sci. Technol. 32(1):57-62.

Collins KA, Hunt WF, Hathaway JM. 2006. Evaluation of various types of permeable pavement with respect to water quality improvement and flood control. In StormCon 2006. Denver, Colorado.

Environment Australia. 2002. Introduction to urban stormwater management in Australia. Department of the Environment and Heritage. Prepared under the Urban Stormwater Initiative of the Living Cities Program 2002.

Ferguson BK. 2006. Progress in porous pavements. In StormCon 2006. Denver, Colorado.

Gerrits C. 2001. Restoration of infiltration capacity of permeable pavers. Master of Science thesis, School of Engineering, University of Guelph, Guelph, Ontario, Canada.

James W. 2004. Clogging of permeable concrete block pavement by street particulates and rain. Innovative modeling of urban water systems, CHI monograph 12. Guelph, Canada.

James W, Gerrits C. 2003. Maintenance of infiltration in modular interlocking concrete pavers with external drainage cells. Practical modeling of urban water systems, CHI monograph 11. Guelph, Canada.

James W, Langsdorff H. 2003. The use of permeable concrete block pavement in controlling environmental stressors in urban areas. In 7 th International Conference on Concrete Block Paving (PAVE AFRICA 2003). Sun City, South Africa. 
Legret M, Colandini V. 1999. Effects of a porous pavement with reservoir structure on runoff water: Water quality and fate of heavy metals. Water Sci. Technol. 39(2):111-117.

Legret M, Colandini V, Le Marc C. 1996. Effects of a porous pavement with reservoir structure on the quality of runoff water and soil. Sci. Tot. Environ. 189/190:335-340.

Pratt CJ, Mantle JDG, Schofield PA. 1990. Porous pavements for flow and pollutant discharge control. In 5th International Conference on Urban Storm Drainage. Osaka, Japan.

Pratt CJ, Mantle JDG, Schofield PA. 1995. UK research into the performance of permeable pavement, reservoir structures in controlling stormwater discharge quantity and quality. Water Sci. Technol. 32(1):63-69.

Roger S, Montrejaud-Vignoles M, Andral MC, Herremans L, Fortune JP. 1998. Mineral, physical and chemical analysis of the solid matter carried by motorway runoff water. Water Res. 32(4):1119-1125.

Sartor J, Boyd GB, Agardy FJ. 1974. Water pollution aspects of street surface contaminants. J. Water Pollut. Control Fed. 46(3):458-465.

Shackel B, Pearson A. 2003. Permeable concrete ecopaving as best management practice in Australian urban road engineering. In $21^{\text {st }}$ Australia Road Research Board (ARRB) Conference. Cairns Qld, Australia.

Stotz G, Krauth K. 1994. The pollution from pervious pavements of an experimental highway section: First results. Sci. Tot. Environ. 146/147:465-470.

Teng Z, Sansalone J. 2004. In situ partial exfiltration of rainfall runoff. II: Particle separation. J. Environ. Eng. 130(9):1-13.

The City of Calgary Wastewater \& Drainage. 2000. Stormwater Management \& Design Manual.
Urban Water Resources Centre. 2002a. Permeable pavement - Port Adelaide Enfield Council car park. Study into permeable pavements for water quality improvement at Port Adelaide-Enfield Council car park, supported by Natural Heritage Trust. Project No. 0767355 .

Urban Water Resources Centre. 2002b. Research into effective life of permeable pavement source control installations. Urban Water Resources Centre Division of IT, Engineering and the Environment. Final Report Project 0767680.

van Duin B, Brown C, Chu A, Marsalek J, Valeo C. 2008. Characterization of Long-Term Solids Removal and Clogging Processes in Two Types of Permeable Pavement under Cold Climate Conditions. In 11th International Conference on Urban Drainage. Edinburgh, Scotland.

Walker DJ, Hurl S. 2002. The reduction of heavy metals in a stormwater wetland. Ecol. Eng. 18:407-414.

Received: 15 June 2008; accepted: 31 August 2008. 